\title{
Neither vitamin E nor donepezil delays progression from amnestic mild cognitive impairment to Alzheimer's disease in the long term
}

Petersen RC, Thomas RG, Grundman M, et al. Vitamin E and donepezil for the treatment of mild cognitive impairment. N Engl J Med 2005; $352: 2379-88$

Do vitamin E or donepezil delay the clinical diagnosis of Alzheimer's disease in people with the amnestic form of mild cognitive impairment?

\section{METHODS}

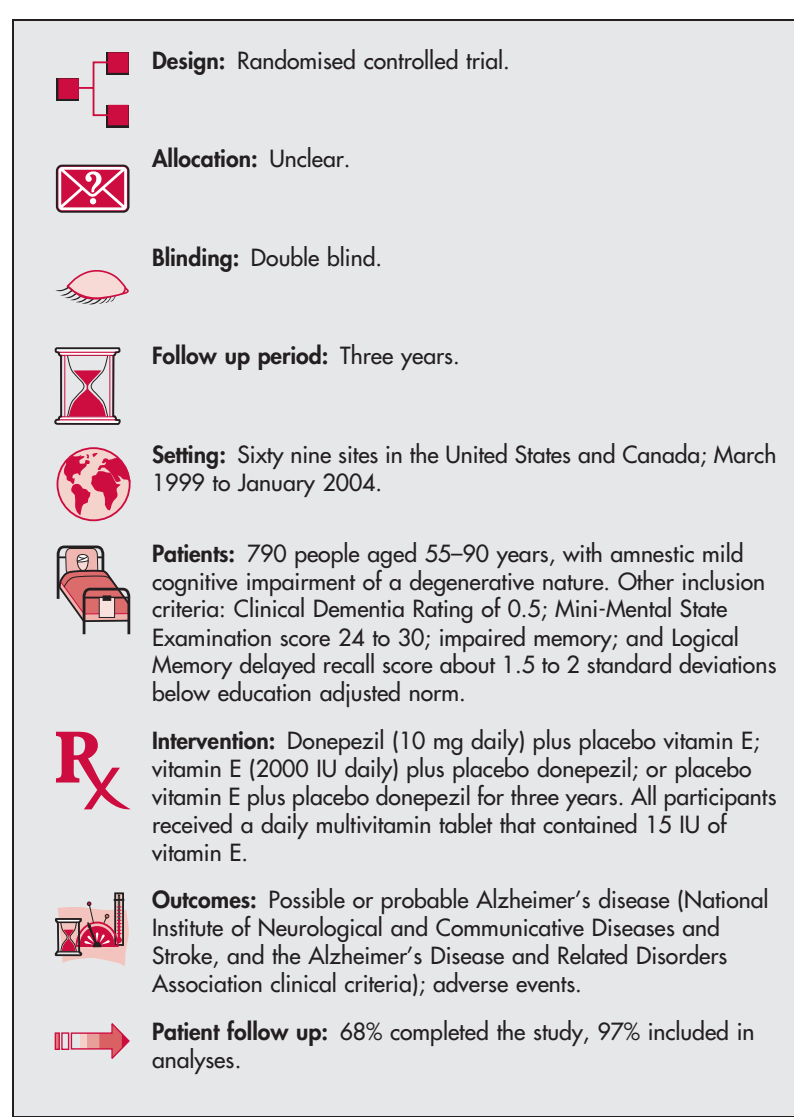

\section{MAIN RESULTS}

Compared with placebo, neither vitamin E nor donepezil altered the probability of progression to Alzheimer's disease after three years (vitamin E $v$ placebo: HR for progression $1.02,95 \%$ CI 0.74 to 1.41 ; donepezil $v$ placebo: HR for progression $0.80,95 \%$ CI 0.57 to 1.13 ). However, there was some indication that donepezil slowed progression to Alzheimer's disease over the first two years compared with placebo $(\mathrm{p}=0.03)$. Donepezil increased adverse events compared with placebo (diarrhoea, muscle cramps, insomnia, nausea, abnormal dreams: $\mathrm{p}<0.01$; loose stools, vomiting, arthritis: $\mathrm{p}<0.05$ )

\section{CONCLUSIONS}

Neither vitamin E nor donepezil were associated with a lower rate of progression to Alzheimer's disease after three years for people with mild cognitive impairment, although donepezil may lower rate of progression in the shorter term.

For correspond Center, Mayo Clinic College of Medicine, 200 First Street SW, Rochester, MN 55905, USA; peter8@mayo.edu

Sources of funding: National Institute on Aging, Pfizer, and Eisai.

\section{Commentary}

The paper by Petersen et al presents the results of a large, carefully conducted, three year clinical trial to examine whether vitamin $\mathrm{E}$ or standard Alzheimer's therapy (the cholinesterase inhibitor donepezil) delays the progression from mild cognitive impairment $(M C I)^{12}$ to Alzheimer's disease (AD). Because $\mathrm{MCl}$ likely represents the prodromal phase of $A D$, when significant neuropathology is already present, ${ }^{3}$ this trial is probably best viewed as a secondary prevention trial. Extensive in vitro evidence supported a potential role for vitamin $E$ in $A D$ prevention, ${ }^{4}$ a wide variety of epidemiological studies suggested that it was protective against $A D, 5$ and a single clinical trial in established $A D$ suggested that it delayed progression. ${ }^{6}$

Alas, the results of the present trial were disappointing. Vitamin $E$ showed no benefit whatsoever, one in a string of negative results for the antioxidant vitamin in the past year. ${ }^{7-9}$ Donepezil showed modest benefits at one year, but the difference between the treatment and placebo groups was gone by the three year end point. The results were somewhat more promising in a post hoc analysis of a subset defined by the $A D$ risk factor gene $A P O E-4,{ }^{10}$ but this likely represents a difference in statistical power (because more such individuals developed $A D$ ) than a true pharmacogenomic difference. Overall, the modest and time limited benefits of donepezil are consistent with $A D$ treatment studies ${ }^{11}$ - not surprisingly, because many investigators believe that $\mathrm{MCl}$ represents the early stage of $A D .^{12}$

Taken together with other recent negative findings about vitamin $\mathrm{E}_{1}^{7-9}$ the present results are likely to discourage the use of vitamin $E$ for prevention of progression in $\mathrm{MCl}$, but do not speak to the larger question of whether vitamin $E$ taken earlier, before the onset of neuropathological changes, might be helpful in the primary prevention of $A D$. For donepezil, the results are less clear, and there is no consensus as to whether it makes sense to continue to offer the drug to individuals with mild cognitive symptoms.

\section{Deborah Blacker, MD, ScD Department of Psychiatry, Mass General Hospital/ Harvard Medical School, Boston, MA, USA}

1 Petersen RC, Smith GE, Waring SC, et al. Mild cognitive impairment: clinical characterization and outcome. Arch Neurol 1999:56:303-8.

2 Petersen RC, Morris JC. Mild cognitive impairment as a clinical entity and treatment target. Arch Neurol 2005;62:1 160-3.

3 Kordower JH, Chu Y, Stebbins GT, et al. Loss and atrophy of layer II entorhinal cortex neurons in elderly people with mild cognitive impairment. Ann Neurol 2001;49:202-13.

4 Luchsinger JA, Mayeux R. Dietary factors and Alzheimer's disease. Lancet Neurology 2004;3:579-87.

5 Behl C, Moosmann B. Oxidative nerve cell death in Alzheimer's disease and stroke: antioxidants as neuroprotective compounds. Biol Chem 2002;383:521-36.

6 Sano M, Ernesto C, Thomas R, et al. A controlled trial of selegiline, alphatocopherol, or both as treatment for Alzheimer's disease: The Alzheimer's Disease Cooperative Study. New Engl J Medicine 1997;336:1216-22.

7 Miller ER 3rd, Pastor-Barriuso R, Dalal D, et al. Meta-analysis: high-dosage vitamin $E$ supplementation may increase all-cause mortality. Ann Int Medicine 2005;1 142:37-46.

8 The HOPE and HOPE-TOO Trial Investigators. Effects of long-erm vitamin E supplementation on cardiovascular events and cancer: A randomized controlled trial. JAMA 2005;293:1338-47.

9 Lee IM, Cook NR, Gaziano JM, et al. Vitamin E in the primary prevention of cardiovascular disease and cancer: the Women's Health Study: a randomized controlled trial. JAMA 2005;294:56-65.

10 Saunders AM, Strittmatter WJ, Schmechel D, et al. Association of apolipoprotein E allele 4 with late-onset familial and sporadic Alzheimer's disease. Neurology 1993;43:1467-72.

11 Courtney C, Farrell D, Gray R, el al. Long-term donepezil treatment in 565 patients with Alzheimer's disease (AD2000): randomised double-blind trial. Lancet 2004;363:2105-15.

12 Petersen RC, Bennett D. Mild cognitive impairment: is it Alzheimer's disease or not? J Alzheimers Dis 2005;7:241-5. 